\title{
A Compact UWB Circular Patch Antenna for X-Band and WLAN Applications
}

\author{
L. Nageswara Rao \\ Asst. Professor, CVR College of Engineering/ECE Department, Hyderabad, India \\ Email: lavurinagesh@gmail.com
}

\begin{abstract}
A composite circular microstrip patch antenna (MPA) with aperture opening for UWB architecture is intended. Double recurrence circular patch configuration along aperture opening slot fed with a microstrip line are planned to achieve coupled recurrence task. The design involves the circular patch and space resonator. The moderation in the radio wire design for the auxiliary band is realized by a $\mathbf{U}-$ shaped resonator. The $U$-shaped aperture is employed in the ground plane to realize dual frequency operation. By modifying structure parameters, the patch works at the $X$ band $(8.69 \mathrm{GHz})$ for satellite communications and parasitic opening works at UNII band $(5.15 \mathrm{GHz})$ for WLAN applications, the two resonators are transmitting with two diverse radiation designs. The designed antenna is small in size, less weight, reduced in cost and satisfactory confinement. The antenna analysis shows the desired return loss $(<-10 \mathrm{~dB})$, improved radiation pattern over working bands. To analyze the attainment of receiving wire, practical specifications, for example, reflection coefficient, data transmission and radiation design are resolved by the recreation of the designed model with HFSS. Designed antenna configuration is appropriate for ultra-wideband applications.
\end{abstract}

Index Terms: Microstrip Patch Antenna (MPA), dual frequency operation, microstrip feed line, UWB, WLAN.

\section{INTRODUCTION}

The fast advancement of wireless networks and developing the specifications for the restricted recurrence operation have incited the hindrance of radio-frequency (RF) ranges and obstruction among them. Multiband antenna assumes a fundamental part of wireless communication specifications and is utilized to meet the needs of various recurrence operation. The patch resonators [1] are in considerable request because of the fast improvement of remote correspondences for the WLAN applications. Consideration of designed antenna is reasonable because of patch resonator is small in size, less weight, reduced cost and satisfactory confinement. A patch antenna can be required to have a larger bandwidth. Different types MPAs such as circular, rectangular, squares with ring slot shapes [2]-[7] have been described in literature. Circular and rectangular patch antennas are having attractive features over the square and ring slot shapes.

The circular patch with aperture opening [8]-[9] is planned and designed for wireless communication systems that can support the UWB [10]-[11] applications. The double recurrence circular patch with space resonator configuration [3] is proposed to attain dual band frequency operation for UWB applications.
The expansive data transfer capacity designated to the allinclusive band frameworks by FCC stretches out from 3.1 to 10.6 GHz, causes exceptionable obstruction with other tight band frameworks in this recurrence band, for example WLAN in the 5.1-5.75 GHz range and furthermore X-band satellite correspondence frameworks working in the 7.75$8.85 \mathrm{GHz}$ space [10]. Therefore, UWB reception apparatuses fit for creating the required stop-bands are adorable. It is proposed to reconfigurable reception apparatuses with notched space for the ideal and effective utilizations of the UWB model [13]-[14].

UWB correspondence frameworks have gotten broad consideration on account of having particular preferences, for example, fast information rate, basic equipment arrangement, high-accuracy running, low power utilization, low intricacy, and ease. On the other hand, to plan UWB reception apparatuses, there are certain difficulties including high radiation productivity, the ultra-wideband execution, consistent gain, and so forth. The MPAs have accomplished extraordinary consideration for UWB reception apparatuses [15] because of a few striking highlights, including low dissemination misfortune, high radiation proficiency, different excitation systems, distinctive patch shapes, almost steady gain, and minimized patch size.

The designed model can be examined as the mix of MPA and other emanating resonator [12], such as a slot resonator. These two elements are tightly coupled together and oscillate at various frequencies. The radiation patterns have different performance levels for wireless communication applications. The WLAN has an essential part in applications, for instance, security frameworks, individual territory organize frameworks, mixed media courses, voice on web convention, cell phones and so forth. At the point when contrasted and old wired LAN arrangements, WLAN offers portability which makes the WLAN [16]-[18] frameworks more easy to understand.

Subsequently the resonator which can give great radiation execution at least two recurrence groups is more attractive and advantageous. In any case, the plan of multiband radio wires are testing and tedious when the span of the receiving wire should be decreased and the groups of task increases.

The prosperity patch antenna resonators in feeding systems need systematic knowledge to couple the resonators and components. However, the resonate encouraging framework set in these portrayed models, for example, microstrip sustained space, co planar space feed and CPWsustained space course of action offers greater adaptability and is specifically good with various mounting surfaces. In this design, so as to maintain a strategic distance from by 
means of gaps, the microstrip feed line is recommended [20]. The microstrip line set on a similar substrate of round fix that could be put straightforwardly finished the feed line. The microstrip feed is simple to model, easy to coordinate by controlling the inset feed position and simple to manufacture.

To emphasize the model, the circular patch configuration along aperture opening slot is planned. It consists of primary band $(8.69 \mathrm{GHz})$ and lower band $(5.1 \mathrm{GHz})$ ranges of the planned resonators are essentially reasonable by the MPA and aperture space consequently. Simulations have been performed using electromagnetic software HFSS provided from Ansys Corporation. The details of UWB antenna design are presented. The simulation results are introduced to feature the execution of the designed receiving wire.

\section{Antenna Configuration}

The circular microstrip patch resonator with aperture opening fed by a microstrip line is designed. The hybrid model includes two different types of resonators; it consists of circular patch and slot. The proposed hybrid structure, the circular [8] patch antenna oscillates at $8.69 \mathrm{GHz}$ and slot [9], oscillates at $5.1 \mathrm{GHz}$ which is reasonable for UWB [10] applications. The design involves the circular patch and space resonator. By shifting the emanating resonators' position, a recurrence tunable MPA can be demonstrated. The feed line is placed at center of the substrate.

The designed model for wireless communications is exhibited in figure 1 . The recommended structure has the dimensions of $40 \mathrm{~mm} \times 40 \mathrm{~mm} \times 1.6 \mathrm{~mm}$, and a FR-4 with a relative permittivity of 4.4 is utilized as a substrate. It comprises of a compact MPA and an inside encouraged microstrip line which is imprinted on a FR-4 substrate. The ground plane is imprinted on the FR-4 substrate with a measurement of $40 \times 40(\mathrm{~L} \mathrm{x} \mathrm{W}) \mathrm{mm}^{2}$. The patch has a radius of $\mathrm{R}=12.5 \mathrm{~mm}$ and offset distance $\mathrm{S}_{1}=18 \mathrm{~mm}$ as shown in Figure 1. The $50-\Omega$ feeding line has a length of $L_{f}=21 \mathrm{~mm}$ and a width of $\mathrm{W}_{\mathrm{f}}=3.0 \mathrm{~mm}$.

The analytical operating frequency of the circular patch antenna is resolved [19] by the consequent equation and analogous to $8.69 \mathrm{GHz}$ which is applicable for $\mathrm{X}$ - band applications.

$$
a=\frac{F}{\left\{1+\frac{2 t}{\pi F \varepsilon_{r}}\left[\ln \left(\frac{\pi F}{2 t}\right)+1.7726\right]\right\}^{1 / 2}}
$$

Where,

$$
F=\frac{8.791 \times 10^{9}}{f_{r} \sqrt{\varepsilon_{r}}}
$$

$a=$ radius of the circular microstrip patch

$\mathrm{t}=$ thickness of substrate

$\varepsilon_{\mathrm{r}}=$ dielectric constant of substrate

$f_{r}=$ resonant frequency

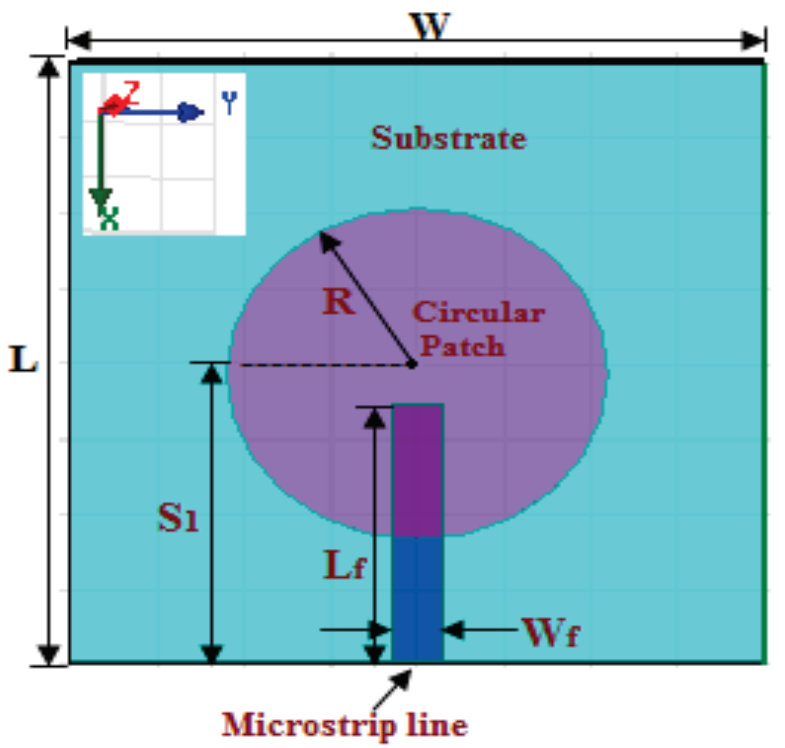

(a)

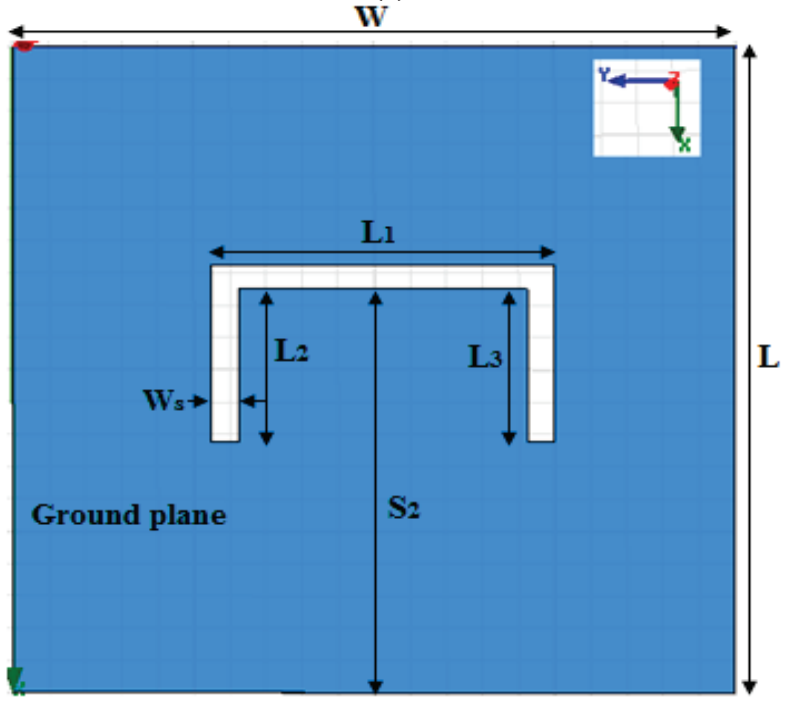

(b)

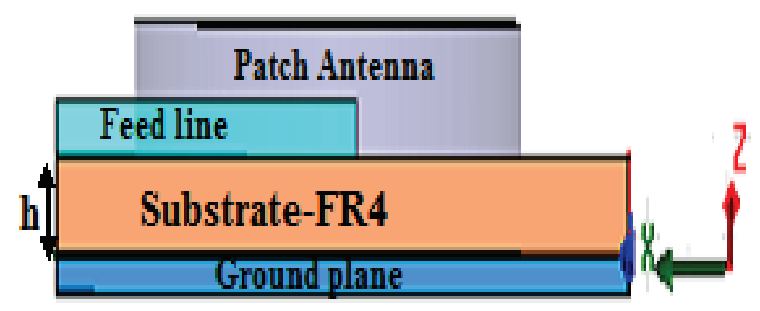

(c)

Figure 1. Proposed MPA with slot: (a) Top view; (b) Bottom view; (c) Side view

In this model, a new type of resonator such as slot etched in ground plane is intended to achieve lower frequency (5.1 $\mathrm{GHz}$ ) band. Fig. 1 exhibits the geometry of opening space. It is notable that by picking a high permittivity substrate, a more prominent size decrease can be accomplished. Thus, the substrate chose for the patch has been FR-4 $\left(\varepsilon_{\mathrm{r}}=4.4\right)$. By changing the opening measurements, the planned structure can works in two groups, and a good impedance coordinate for the working frequencies can be effectively achieved. 
The design consideration for the lower excited slot antenna comprises of three rectangular spaces with different length and selected width $\mathrm{W}_{\mathrm{S}}=0.5 \mathrm{~mm}$ as appeared in Figure 1 , different rectangular space lengths are $\mathrm{L}_{1}=16 \mathrm{~mm}, \mathrm{~L}_{2}=5.5$ $\mathrm{mm}, \mathrm{L}_{3}=5.5 \mathrm{~mm}$ and counterbalance separation of opening is $\mathrm{S}_{2}=22 \mathrm{~mm}$. By modifying the-opening parameters, the proposed structure can work in two groups, and a good impedance coordinate for the working frequencies can be effectively acquired. By adjusting the structure parameters, the circular patch and slot resonates at $8.69 \mathrm{GHz}$ and 5.1 $\mathrm{GHz}$ respectively. The shape of the structure has been chosen such that, it meets the necessity of data transmission and small in size consequently. The intended structure enables the affirmation of a dual band task without expanding the patch dimensions.

\section{RESUlts AND Discussions}

Fig. 2 represents the simulated return loss of the intended MPA. The lower energized band is because of the space while the auxiliary band is because of the round microstrip fix radio wire. It represents $-30 \mathrm{~dB}$ and $-44 \mathrm{~dB}$ return loss at $5.1 \mathrm{GHz}$ and $8.69 \mathrm{GHz}$ consequently. Note that there are no frequencies to be evidently the nearness of indirect fix, that is, the full resound opening mode is started by the fix radio wire.

The arrival misfortune is another approach for expressing mismatch. It is a logarithmic proportion estimated in $\mathrm{dB}$ that thinks about the power reflected by the radio wire to the power that is sustained into the receiving wire from the transmission line.

The data transfer capacity basically characterizes the recurrence run over which a receiving wire meets a specific arrangement of determination execution criteria. The critical issue is to consider in regards to data transfer capacity is the execution tradeoffs between the majority of the execution properties portrayed previously.

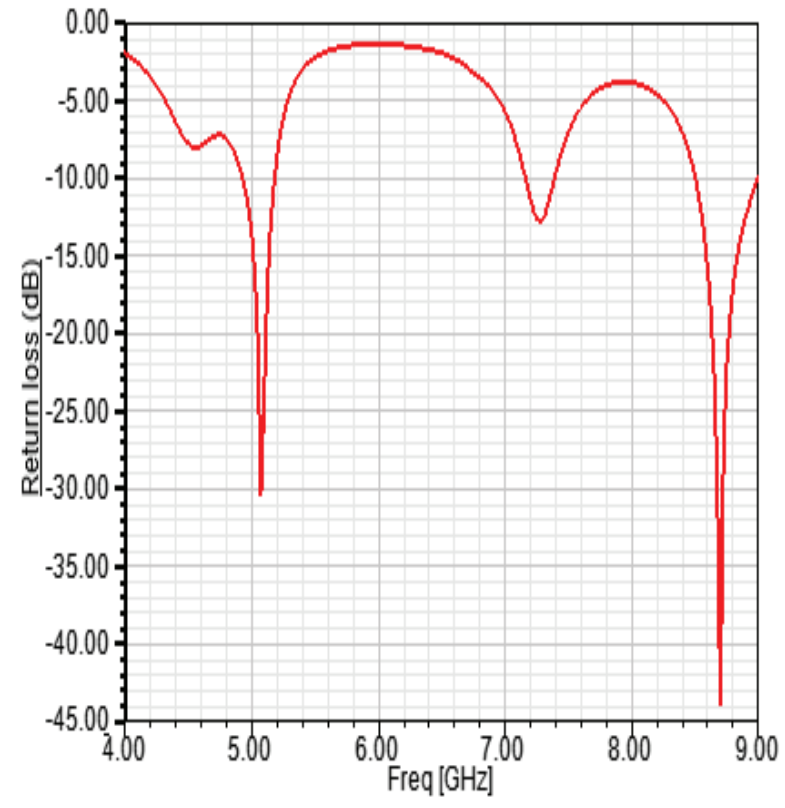

Figure 2. Simulated return loss at $5.1 \mathrm{GHz}$ and $8.69 \mathrm{GHz}$
The radiation example of the reproduced radio wire structure at $5.1 \mathrm{GHz}$ and $8.69 \mathrm{GHz}$ with phi=0 (deg) and phi $=90$ (degree) are depicted in Fig. 3. The intended receiving wire transmits a most extreme in the broadside heading at $8.69 \mathrm{GHz}$ and slot - opening resonator is radiating the waves in bidirectional at $5.1 \mathrm{GHz}$. The radiation examples of a radio wire give the data that depicts how the reception apparatus coordinates the vitality it transmits. Radiation designs are for the most part exhibited on a relative power $\mathrm{dB}$ scale.

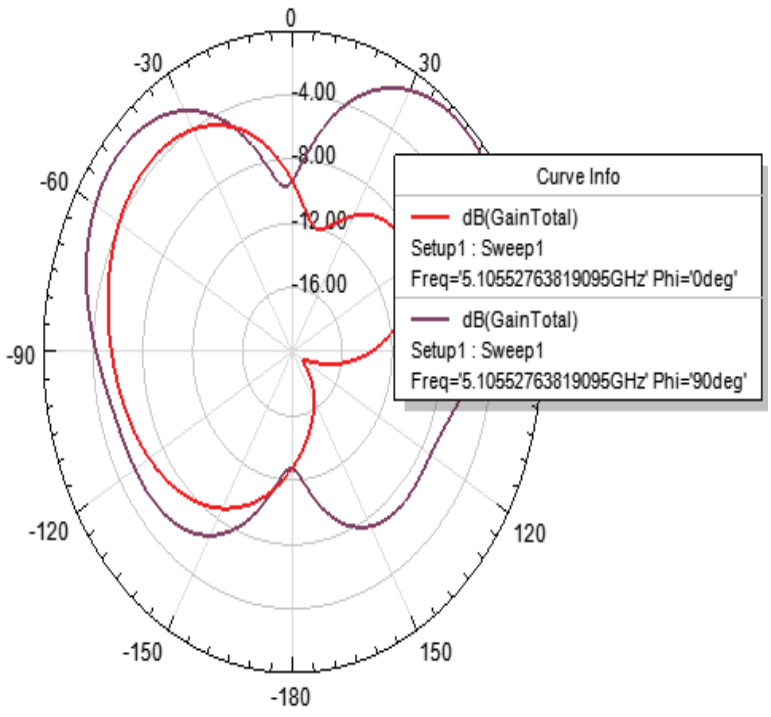

(a)

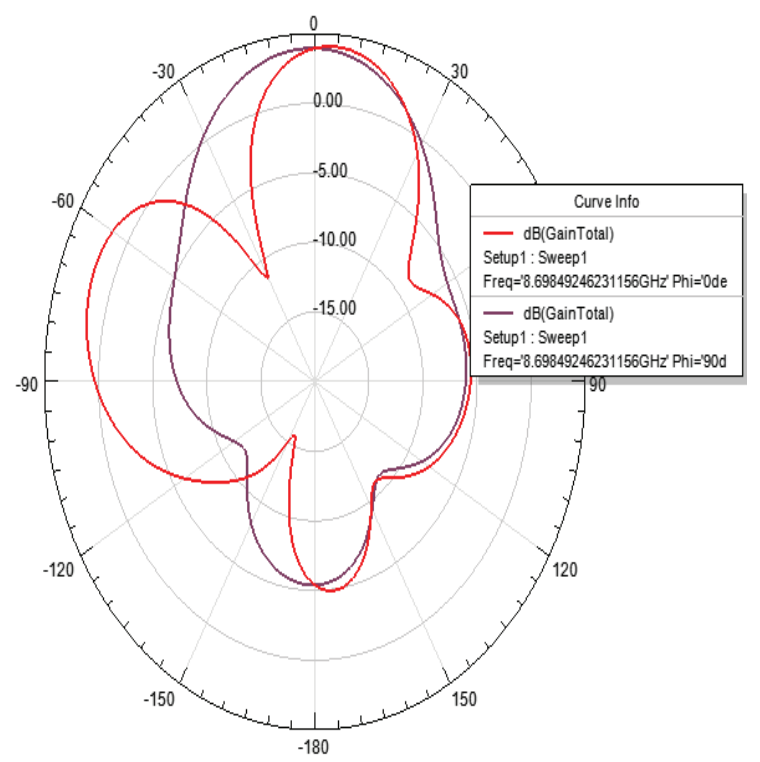

(b)

Figure 3. Radiation patterns at $5.1 \mathrm{GHz}$ and $8.69 \mathrm{GHz}$

Fig. 4(a) and (b) represents the designed configuration gain at $5.1 \mathrm{GHz}$ and $8.69 \mathrm{GHz}$ as $4 \mathrm{dBi}$ and $5.1 \mathrm{dBi}$ consequently. The most extreme radiation is directed outside in both the recurrences. 


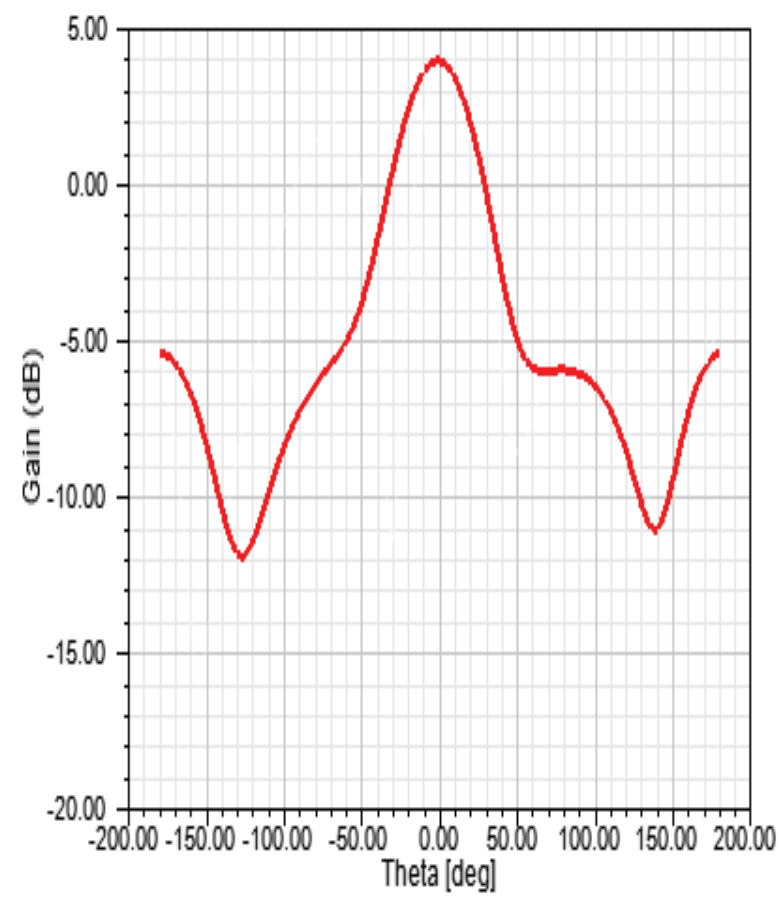

(a)

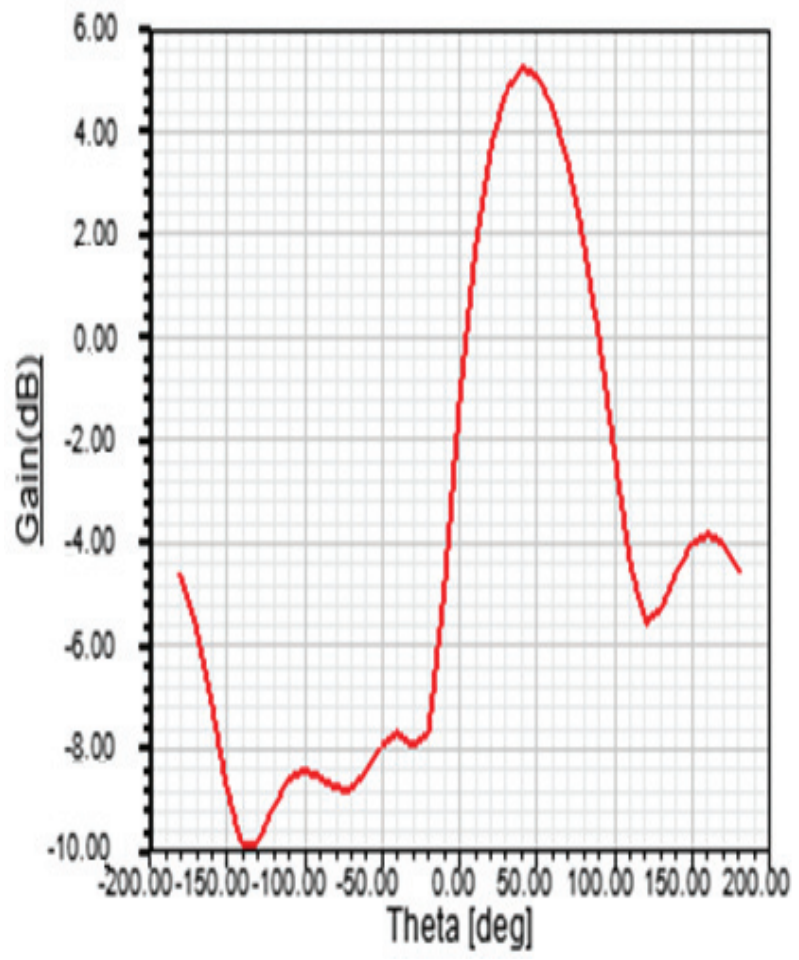

(b)

Figure 4. Simulated Gain at (a) $5.1 \mathrm{GHz}$ and (b) $8.69 \mathrm{GHz}$

Fig. 5(a) and (b) represents the VSWR of the intended model. It depicts the analysis of the inclined line and load. For perfect case estimation the VSWR is 1 . The investigated model has VSWR of 1.05 at $8.69 \mathrm{GHZ}$ and 1.1 at 5.1 GHZ. The VSWR exhibit that how intently a radio wire's terminal impedance is composed to the trademark impedance of the slanted line.

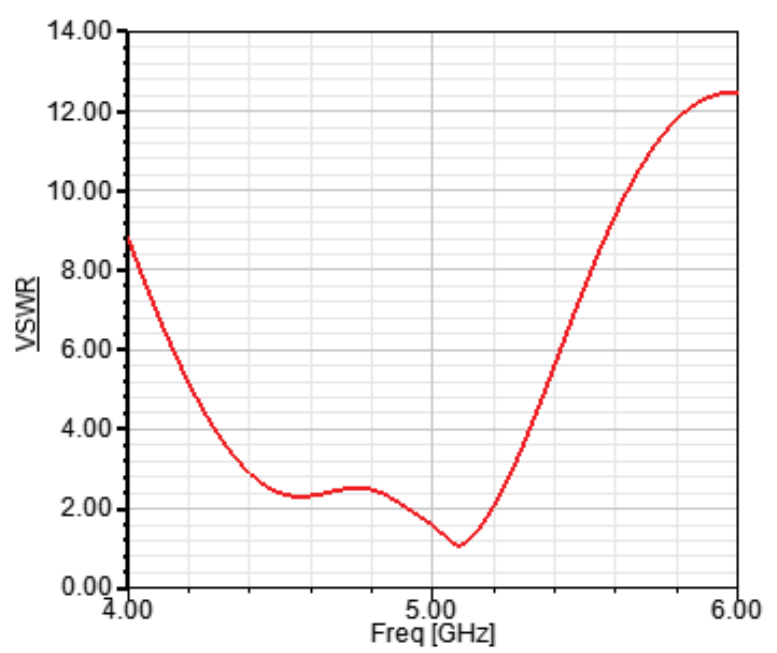

(a)

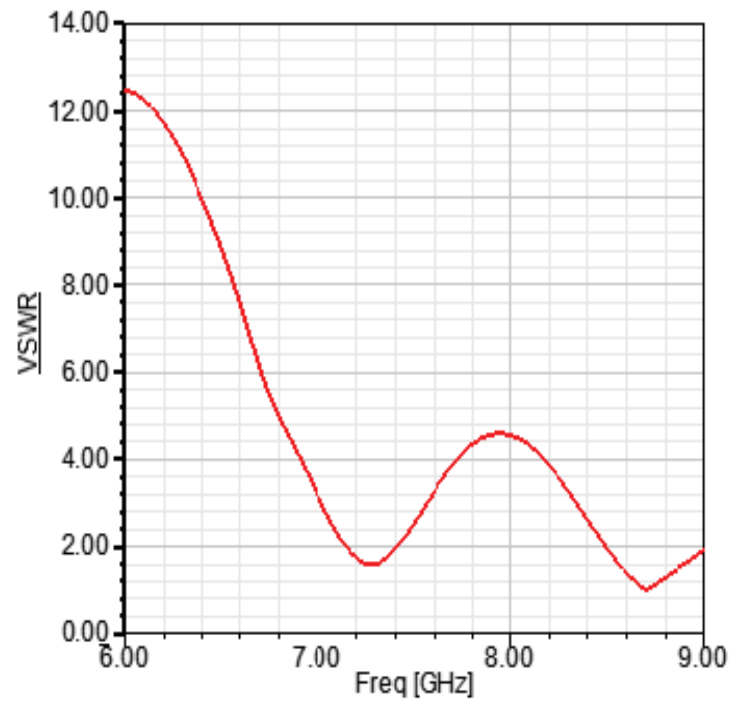

(b)

Figure 5. Simulated VSWR at (a) $5.1 \mathrm{GHz}$ and (b) $8.69 \mathrm{GHz}$

\section{Conclusions}

A composite circular patch with aperture opening is intended for UWB systems. The planned circular patch structure with aperture space configuration is realized to procure the $\mathrm{X}$ - band $(8.69 \mathrm{GHz})$ and WLAN $(5.1 \mathrm{GHz})$ band. The recommended configuration is attainable and outline parameters are recognized by using description similarity. An intended model contour has been reproduced and it represents that return loss of $-44 \mathrm{~dB},-31 \mathrm{~dB}$ at the resonant recurrences of X-band $(8.69 \mathrm{GHz})$ and WLAN band $(5.1 \mathrm{GHz})$ correspondingly. The reconfigurable structure has the capacity of delivering recurrence indents for the UWB frameworks, to take out obstruction with WLAN (4.92- $5.2 \mathrm{GHz})$ and X-band of satellite correspondence frameworks $(8.25-8.81 \mathrm{GHz})$. The illustrated model takes a less volume, smaller size, basic shape and satisfactory operational data transfer capacity, with the end goal that it is appropriate for ultra - wideband applications. 


\section{REFERENCES}

[1] Sekhar M, S. N. Bhavanam, Dr. P. Siddaiah, "Triple Frequency Circular Patch Antenna",IEEE International Conference on Intelligence and computing Research, pp. 1-3, December 2014.

[2] R. Srivastava, S. Ayub, V. K. Singh, J. P. Saini, "Dual Band Rectangular and Circular Slot Loaded Microstrip Antenna for WLAN/GPS/WiMax Applications",Fourth International Conference on Communication Systems and Network Technologies,pp. 45-48, April 2014.

[3] S. I. Hussain Shah, S. Bashir, S. D. Hussain Shah, "Compact Multiband microstrip patch antenna using Defected Ground structure (DGS)", The 8th European Conference on Antennas and Propagation (EuCAP), pp. 2367-2370, April 2014.

[4] M. I. Sabran, S. K. A. Rahim, M. F. M. Yusof, A. A. Eteng1, M. Z. M. Nor, I. M. Ibrahim ,"Miniaturized Proximity Coupled Antenna with Slot Ring as Defected Ground Structure", IEEE Symposium on Wireless Technology and Applications (ISWTA), pp.81-85, Sept-oct 2014.

[5] Lakshmikanth, P., Takeshore, K., \& Madhav, B. T. P. (2015). Printed log-periodic dipole antenna with notched filter at 2.45 $\mathrm{GHz}$ frequency for wireless communication applications. Journal of Engineering and Applied Sciences, 10(3), 40-44. doi:10.3923/jeasci.2015.40.44.

[6] M. H. Tariq, S. Rashid, F. A. Bhatti,"Dual Band Microstrip PatchAntenna for WiMAX and WLAN Applications", International journal of Multidisciplinary and Currentresearch, vol.2,pp. 104-108, Jan/Feb 2014.

[7] S. C. Gao, L. W. Li, T. S. Yeo, M. S. Leong,"Small DualFrequency Microstrip Antennas", IEEE Transactions on VehicularTechnology,vol.51,No.1,pp. 1916-1917, January 2002.

[8] Garima,D.Bhatangar,J.S.Saini,V.K.Saxena,L.M.Joshi, "Design of Broadband Circular Microstrip Patch Antenna With Diamond Shaped Slot",Indian Journal of Space And Physics,vol.40,pp.275-278, October 2011.

[9] J. A. Ansari, A. Mishra, N. P. Yadav,P. Singh , "Dualband Slot Loaded Circular Disk Patch Antenna for WLAN Application", International Journal Of Microwave And Optical Technology, vol.5, No.3, pp. 124-129, May 2010.

[10] Clementi, G., Fortino, N., Dauvignac, J.-Y., et al.: 'Frequency and time domain analysis of different approaches to the backing of an UWB slot antenna', IEEE Trans. Antennas Propag., 2012, 60, (7), pp. 3495-3498.

[11] Ojaroudi, N., Ojaroudi, M.: 'Novel design of dual bandnotched monopole antenna with bandwidth enhancement for UWB applications', IEEE Antennas Wirel. Propag. Lett., 2013, 12, pp. 698-701.

[12] G.P.Gao,M.Li,S.F.Niu,X.J.Li,B.N.Li,J.S.Zang, “Study Of Novel Wideband Circular Slot Antenna Having Frequency Band Notched Function",Progress In Electromagnetic Research(PIER)96, pp.141- 154,2009.

[13] Ryu, K.S., Kishk, A.: 'UWB antenna with single or dual band-notches for lower WLAN band and upper WLAN band', IEEE Trans. Antennas Propag., 2009, 57, (12), pp. 39423950.

[14] Li, Y., Li, W., Yu, W., et al.: 'A small multi-function circular slot antenna for reconfigurable UWB communication applications'. IEEE Antennas and Propagation Society Int. Symp. (APSURSI), 2014, pp. 834-835.

[15] Kalteh, A.A., DadashZadeh, G.R., Naser-Moghadasi, M., et al.: 'Ultrawideband circular slot antenna with reconfigurable notch band function', IET Microw. Antennas Propag., 2012, 6, (1), pp. 108-112.
[16] Kishan Kumar K., Prasanth, Edward Stephen, A novel design approach and simulation of frequency reconfigurable microstrip patch antenna for Wi-Fi, WLAN and GPS applications, IEEE, International Conference on Robotics, Automation, Control and Embedded Systems, India, pp. 1-4, Feb. 2015.

[17] Xinghui Zhang, Dongya Shen, Lan Li, and Huiyun Liu., A Compact frequency reconfigurable antenna applied to WLAN/WiMAX, Shanghai, China, , pp. 1-7, Oct. 2011.

[18] Q. Zhong, Y. Li, H. Jiang, Y. Long,"Design of a Novel Dualfrequency Microstrip Patch Antenna for WLAN Applications",Antennas And Propogation Society International Symposium,vol.1, pp. 277-280,June 2004.

[19] C. A. Balanis, "Antenna Theory, Analysis and Design”, Second edition, John Wiley andSons, NewYork, 1997.

[20] R. A. Kranenburg and S. A. Long, , "Microstrip Transmission Line Excitation of Dielectric Resonator Antennas," Electron. Lett. vol. 24, pp.1156-1157, 1988. 